the supposition that these two princes were half-witted or for some other reason incapable of exercising the imperial authority, though they might bear the imperial title. In this case they would hardly appear in a public procession, and it would be necessary to provide a capable successor, whom the Emperor would naturally wish to unite by marriage with his own family. After the birth of Michael III such a successor was no longer needed, and an excuse was therefore found for degrading Alexios. This supposition also supplies a reason for the omission of all reference to these two sons in the literary authorities.

London.

E. W. Brooks.

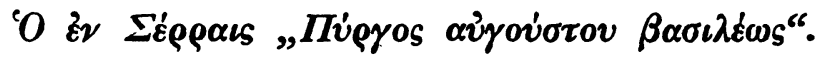

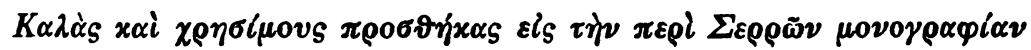

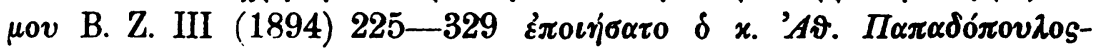

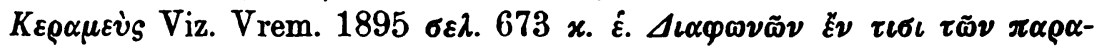

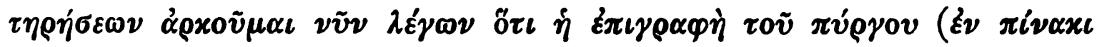

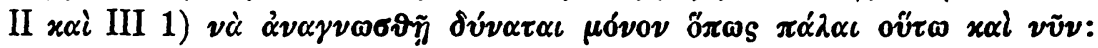

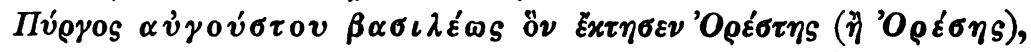

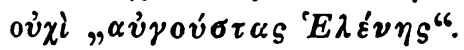

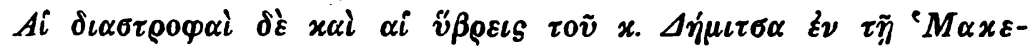

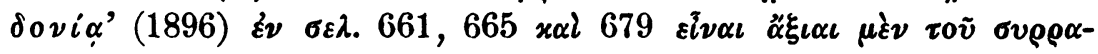

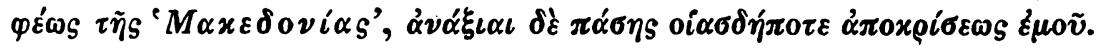

'Ev $\Theta \varepsilon \sigma \sigma \propto \lambda o v i x \eta$.

II. N. $\boldsymbol{I I}$.

\title{
Za Nikephoros Blemmydes, B. Z. X 419 (Bury).
}

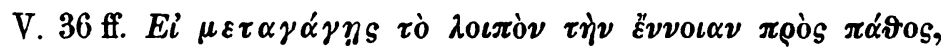

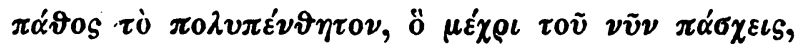

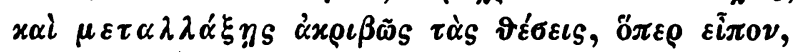

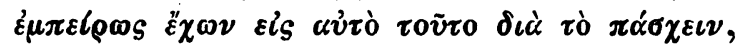

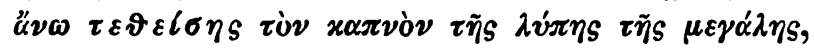

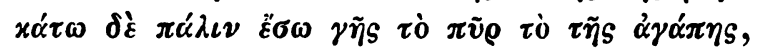

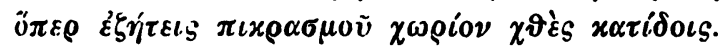

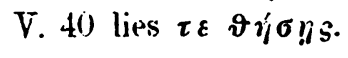

Saloniki. P. N. P. 